\title{
A formação do professor pesquisador a partir da pedagogia de projetos: uma integração possível
}

\section{The education of teachers as researchers based on the pedagogy of projects: a possible integration}

\author{
Amarildo Menezes GONZAGA*
}

Resumo: O presente texto trata da formação do professor pesquisador a partir da pedagogia de projetos, tomando como referência a metodologia Aprender InvestigandoA/I, desenvolvida na disciplina Pesquisa e Prática Pedagógica I, com alunos do quinto período do Curso Normal Superior, da Universidade do Estado do Amazonas (UEA). A pesquisa foi constituída de duas etapas. A primeira incide na proposição de fundamentos teóricos pautados em reflexões sobre a relação entre pesquisa em educação e a formação do professor pesquisador, considerando-se a integração entre a pedagogia de projetos e a interdiscipli-naridade. A segunda indica como foi aplicada a metodologia A/ I, desde a socialização do plano de ensino da disciplina até os projetos de pesquisa coletivamente construídos, e apresenta as respectivas impressões dos sujeitos participantes do processo.

Palavras-chave: professor pesquisador. pedagogia de projetos. interdisciplinaridade.

Abstract: This article discusses the education of teachers as researchers based on the pedagogy of projects. It takes as reference the methodology Learning-Investigating L/I developed in the Pedagogical Research and Practice I module with students of the fifth period of the Regular High Level Course - University of the State of Amazon (UEA). The research was organized in two phases. The first phase consists of the proposition of the theoretical basis informed by the reflections about the relation between research in education and the education of teachers as researchers, considering the integration between the pedagogy of projects and interdisciplinary teaching. The second phase demonstrates how the methodology was applied, from the socialization of the plan of teaching of the course to the research projects which were collectively designed, and it also presents the impressions of the participants involved in the process.

Keywords: teachers as researchers. pedagogy of projects. interdisciplinary teaching.

* Doutor em Educação, Universidade do Estado do Amazonas e CEFET-AM, amarildogonzaga@vivvax.com.br

Olhar de professor, Ponta Grossa, 9(1): 47-62, $2006 . \overline{47}$ 


\section{INTRODUÇÃO}

O registro das experiências pedagógicas precisa ser uma prática cotidiana no processo de formação do professor que pretende se legitimar a partir da relação entre os pares ensino e pesquisa, principalmente se considerarmos que a pesquisa advém das inquietações oriundas do ensino que, por sua vez, sem aquela é incapaz de retroalimentar-se. Por outro lado, se observarmos as inúmeras atividades que os professores desenvolvem no cotidiano escolar, será possível percebermos o quanto a pesquisa, em vez de ser prazerosa, acaba sendo um grande desafio. No entanto, não é nossa intenção levantarmos esse tipo de situação, apenas resolvemos mencionála, por ser um problema que começou a nos inquietar neste momento. Em uma outra oportunidade, apresentaremos um estudo a respeito.

Organizamos este trabalho em dois momentos. O primeiro refere-se à construção dos fundamentos teóricos relativos à temática em questão. Para tanto, fizemos uma reflexão sobre a relação existente entre a pesquisa em educação e a formação do professor pesquisador. Procuramos nos deter em situações do próprio cotidiano do professor, assim como nos entraves que ele enfrenta, quando decide pela prática pedagógica atrelada à pesquisa. Adotamos, para efeito de respaldar nossos fundamentos, algumas posições de teóricos como Bachelard (1996) e Meksenas (2002). Em segui- da, apresentamos a necessidade da relação entre a pedagogia de projetos e a interdisciplinaridade, como elementos integradores no processo de formação do professor pesquisador.

No segundo momento, preocupamo-nos em apresentar e analisar alguns comentários sobre a aplicação de uma metodologia centrada na Pedagogia de Projetos, que vivenciamos com um grupo de alunos do Curso Normal Superior da Universidade do Estado do Amazonas. Antes de descrevermos as etapas que a compõem, gostaríamos de salientar que, apesar de o semestre haver terminado e os alunos terem concluído a disciplina, redimensionamos aquela atividade, a partir da orientação de seis projetos de pesquisa individuais de um grupo de alunos daquele curso, que agora estão engajados na pesquisa, desenvolvendo seus respectivos projetos, atrelados ao período de estágio supervisionado. A seguir, detalharemos as etapas mencionadas.

\section{APESQUISAEM EDUCAÇÃOEA FORMAÇÃO DO PROFESSOR PESQUISADOR}

O ato científico precisa advir de um sentimento capaz de ser interpretado, principalmente por quem o pratica, além das fronteiras de qualquer tempo e espaço preestabelecidos. Sendo assim, fazer uso da ciência incide, da parte do pesquisador, em saber administrar os inúmeros desafios que podem comprometer as perspectivas de pes- 
quisa.

Ao tratarmos de pesquisa em educação, se considerarmos o ato de pesquisar como "a capacidade de produzir um conhecimento adequado à compreeensão de determinada realidade, fato, fenômeno ou relação social" (MEKSENAS, 2002, p. 22), perceberemos que inúmeros desafios serão possíveis de ser encontrados. Dentre eles mencionamos o privilégio que é dado à transmissão de conteúdos, em detrimento do processo de construção de conhecimentos; o prevalecimento de fins imediatistas e utilitários; as contínuas xerox e as "fábricas" de artigo científico, mono-grafias, dissertações e até mesmo de teses; a diminuição de recursos para financiamento de pesquisas; a dificuldade em legitimar a dupla identidade dos docentes, que têm de ser tanto professores quanto pesquisadores (MEKSENAS, 2002).

De todos os desafios que mencionamos no parágrafo anterior, nos ateremos neste estudo ao último, por considerarmos que a partir dele incidem os demais. Para enfocá-lo nesta pesquisa, atribuiremos sua condição a um dos legados do positivismo. A exemplo, ainda experienciamos a hierarquização entre o trabalho intelectual e manual no cotidiano da própria universidade, que se legitima através das inúmeras unificações, que também ainda são imperantes (o método único, a reforma única, o procedimento único etc.).

Especificando ainda mais os efeitos da hierarquização entre o traba- lho intelectual e o trabalho manual, citamos a intensividade com que o professor constrói a identidade na condição daquele que ensina. No cotidiano escolar, desenvolve suas práticas pedagógicas a partir das produções intelectuais de pesquisadores de renome, muitas vezes até nem ousa colocar em questão a ideologia que sustenta as "verdades" apresentadas na obra estudada. Construir a outra identidade, ou seja, a de pesquisador, implicaria ao professor não só colocar em questão "as verdades" dos teóricos de renome, mas também redimensionar aquele tipo de exercício, disponibilizando sua própria produção para ser refutada, em um contínuo exercício do princípio de que

toda cultura científica deve começar por uma catarse intelectual e afetiva. Resta, então, a tarefa mais difícil: colocar a cultura científica em estado de mobilização permanente, substituir o saber fechado e estático por um conhecimento aberto e dinâmico, dialetizar todas as variáveis experimentais, oferecer, enfim, à razão razões para evoluir (BACHELARD, 1996, p. 26).

Por outro lado, para que aquele tipo de exercício se torne uma prática contínua, é indispensável um esforço não apenas de ordem ou de exigência profissional do educador. O propósito vai mais além, pois é um sentimento que está comprometido com o seu íntimo, com a sua realização pessoal, com o seu projeto de vida; com a necessidade de redimensionar os resultados de suas descobertas para que 
o outro também possa realizar-se pessoalmente, independente de retorno financeiro.

Conforme defende Bachelard, todo professor pode escolher ser apenas professor, ou apenas pesquisador. Mas agir a partir dessa perspectiva de escolha implicará a não legitimação de uma ciência para a democracia, principalmente no âmbito educacional, que só ocorre,

quando todo pesquisador se reconhece como professor e, do mesmo modo, todo professor se reconhece como pesquisador. A superação do pesquisador e do professor em si (o primeiro caso), atingindo uma ação de conhecimento por si (o segundo caso), contribui para a hierarquização existente entre trabalho intelectual e trabalho manual, entre dirigentes e dirigidos (1996, p. 26).

Dessa maneira, percebe-se o quanto é imprescindível a evidência de ambas identidades (professor e pesquisador) no processo de construção da história do educador. No âmbito educacional, ao buscar a legitimação da identidade de professor e de pesquisador simultaneamente, quebrarse-á o paradigma de que a ciência é uma prática especializada, desenvolvida por especialistas com uma formação intelectual sofisticada. Será possível, também, "não ser presa fácil das concepções que ora superestimam, ora subestimam a educação escolar; ora subestimam a pesquisa como instrumento de inserção do professor na realidade escolar" (MEKSENAS, 2002, p. 25).

\section{A PEDAGOGIA DE PROJETOS E A INTERDISCIPLINARIDADE: DOIS EIXOS INTEGRADORES NA FORMAÇÃO DE PROFESSORES PESQUISADORES}

Em decorrência do exposto, é necessário que cada vez mais nos aproximemos da prática e busquemos sentido aos possíveis princípios pedagógicos que contribuirão para uma nova organização curricular, capaz de atender às necessidades e anseios no processo de formação do professor pesquisador.

Consideramos, a partir de nossa experiência, a pedagogia de projetos como uma primeira vertente da mencionada organização curricular, principalmente se levarmos em consideração a flexibilidade que a envolve, assim como as possibilidades de construção do conhecimento centradas em interesses e expectativas dos sujeitos envolvidos no processo, e suas relações com os seus respectivos objetos. De acordo com essa prática pedagógica, é possível ainda proporcionar uma construção coletiva do conhecimento, problematizando e contextualizando questões relacionadas à vida do jovem, conduzindo-o a possibilidades de perceber e se deparar com a diversidade, dando a ela um tratamento desafiador, capaz de driblar a linearidade, a fragmentação dos componentes curriculares e os demais paradigmas que engessam o sistema escolar.

A segunda vertente refere-se à interdisciplinaridade, a qual, por não 
se limitar apenas à mera justaposição de disciplinas, pode ser legitimadora da pedagogia de projetos. É, na verdade, um processo que conduz diferentes conhecimentos a manterem um diálogo aprofundado a respeito de uma determinada temática, a partir de diferentes possibilidades de métodos e procedimentos capazes de proporcionarem condições de conhecer, negando, afirmando e sintetizando o objeto que esteja sendo evidenciado, em uma multiplicidade de interações capazes de explicarem, intervirem, mudarem e preverem o novo. Na seqüência, discorreremos sobre os fundamentos teóricos que norteiam este estudo.

\subsection{A PEDAGOGIA DE PROJETOS LEGITIMADA A PARTIR DA INTERDISCIPLINARIDADE}

A pedagogia de projetos não incide apenas em articular atividades a partir de uma finalidade estabelecida em função de uma exigência. Nem tampouco é uma estratégia de aprendizagem que visa ao alinhavo de conhecimentos, para efeito de agregação de pessoas e resolução de problemas no contexto escolar. Sua intenção vai muito mais além, se tomarmos como referência os pressupostos antropológicos que a sustentam, pois ela objetiva

que os envolvidos se tornem atores sociais e, para fazê-lo, baseiem-se em uma filosofia da experiência que não separe a teoria da prática. [...] a pedagogia de projetos atua, como pedago- gia da apropriação e é assimilável ao modo de trabalho pedagógico " de tipo apropriativo" centrado na inserção social (BOUTINETI, 2002, p. 197).

Ademais, internalizar a pedagogia de projetos decorrente daquela perspectiva implicará repensar os próprios conceitos do saber e do fazer pedagógico, com o intuito não só de consubstanciar matizes inovadores, mas também de criar alternativas de sobrevivência e perspectivas futuras, em uma sociedade em que o pragmatismo e o ceticismo são fatores determinantes. Sendo assim, ela não só retroalimenta a vida de quem por ela opina, mas possui vida própria. $\mathrm{Na}$ verdade, da mesma forma procede com os indivíduos que por ela opinam, assim como eles também acabam fazendo em proporções similares. Por isso, um projeto qualquer, definido fora dos alunos, confiscado para seus próprios fins por um grupo de agentes administrativos, ou de professores, engendrará nos alunos reflexos tradicionais de passividade, até rejeição (2002, p.198).

Considerando os aspectos descritos, é imprescindível que sejam adotados mecanismos capazes de legitimar a pedagogia de projetos em sua essência. Para tanto, parece-nos conivente comentarmos sobre um dos mecanismos que acreditamos ser possível de adoção e aplicação: a interdisciplinaridade. Essa possibilidade aparece quando a visualizamos a partir da

ciência como um constructo humano

Olhar de professor, Ponta Grossa, 9(1): 47-62, 2006. $\overline{51}$ 
que, para construir conhecimento válido, precisa olhar a natureza como um todo. Portanto, nada mais razoável do que a busca de uma visão de conjunto, capaz de integrar as diversas dimensões disciplinares e trandisciplinares (ALMEIDA, 2000, p. 41).

Pensar a interdisciplinaridade sem considerar uma concepção que a sustente passa a ser leviano. Ademais, podemos incorrer no erro de encerrála em si própria, contribuindo para que aquilo que poderia ser complexo, prazeroso e proveitoso no processo de desconstrução e reconstrução do conhecimento, vinculado a uma relação de aproximação e ressignificação entre teoria e pratica, acabasse se transformando em um conjunto de atividades banalizadoras e reprodutoras de elementos oriundos de conhecimentos normatizados pela academia. Em decorrência disso, acreditamos ser interessante pensar na interdisciplinaridade centrando-nos na fenomenologia, na condição de corrente de pensamento, visto que

em nenhum momento está interessada em colocar em relevo a historicidade dos fenômenos. A busca da essência, isto é, o que o fenômeno verdadeiramente é, depois de sofrer um isolamento total, uma redução, eliminando o eu que vivencia e o mundo com seus valores, cultura etc., carece de toda referência que não seja a de sua pureza como fenômeno (TRIVIÑOS, 1987, p. 47).

Desse modo, aquilo que poderia ser objeto passa a ser interpretado como fenômeno e, assim, passa a ser ressignificado a partir de uma relação mediatizadora com o sujeito cognoscente. Nessa ressignificação, ele deixa de ser mero objeto no processo de construção do conhecimento empreendido pelo sujeito. Ambos, na verdade, complementam-se com o intuito de atender às inquietações que emergem dos múltiplos olhares que tentam compreender e interpretar as possibilidades de legitimação, mesmo que circunstancial. .

Partindo para a segunda etapa deste trabalho, apresentaremos a experiência que vivenciamos com alunos do quinto período do curso Normal Superior da Universidade do Estado do Amazonas, no segundo semestre do ano de 2004.

\section{A ARTICULAÇÃO ENTRE OS PRESSUPOSTOS TEÓRICOS E METODOLÓGICOS DO OBJETO DESTE ESTUDO}

\subsection{AMETODOLOGIA APRENDER INVESTIGANDO (A/I)}

Quando fomos convidados a ministrar a disciplina Pesquisa e Prática Pedagógica I, no segundo semestre de 2004, para alunos do quinto período do curso Normal Superior da Universidade do Estado do Amazonas, ao estudarmos a respectiva ementa, relacionado-a ao Projeto Político Pedagógico daquele curso, percebemos um grande desafio: legitimar aqueles pressupostos teóricos na prática, tomando como referência o cotidiano daque- 
les futuros professores. Diante disso, começamos a pensar em uma metodologia capaz de vencer aquele desafio. Para tanto, como pretexto para legitimar a pedagogia de projetos como estratégia na formação de professores pesquisadores, utilizamos uma metodologia denominada "Aprender Investigando", criada pelo Prof. Dr. Martín Rodríguez Rojo, catedrático da Universidad de Valladolid - Espanha. Tal metodologia constitui um nível de intervenção mais concreto e a curto prazo, podendo acontecer no espaço de sala de aula, inclusive. Está centrada em um modelo sistêmico de base curricular proposto pelo mesmo autor, denominado de Modelo Ecológico Comunicativo, que tem suas esferas substanciais constituídas de

microsistema, el mesosistema, el exosistema y el macrosistema. Definidas en relación com su influencia en el desarrollo del sujeto, ubicado siempre en un entorno, del cual no puede prescindir, porque la persona humana es un ser ubicado en el espacio y delimitado por el tiempo. Cada una de esas esferas abarca una serie de elementos que se relacionan entre sí dentro de cada una y com los de las otras. [...] Es sistémico, es englobante, es interdisciplinar e integral (ROJO, 1997, p. 149-150)

Por reunir uma série de condições similares que caracterizam o modelo descrito anteriormente, a metodologia $\mathrm{A} / \mathrm{I}$ não deixa de respeitar os princípios de tal modelo. Dentre essas condições, podemos mencionar as descritas por Rojo (p.160-161).
- A pesquisa parte da análise da prática escolar. Parte do mundo da vida no próprio cotidiano da sala de aula, das idéias prévias dos alunos, de seus preconceitos, de suas imagens do mundo, dos sujeitos que se entendem entre si como observadores participantes da sociedade, do mundo vivido, ainda que não problematizado pelos sujeitos, de suas crenças, de seus valores, dos conhecimentos populares que o aluno possui, de suas suspeitas de seu saber implícito.

- A pesquisa conta com a relação biótipo-biocenose e com o significado que os pesquisadores atribuem tanto a essa relação como aos próprios problemas e conflitos decorrentes da intuição ou gerados pela preocupação da comunidade educacional.

- A pesquisa examina previamente os recursos, o espaço escolar, a temporalização de suas fases e a organização de todas as disponibilidades.

- A pesquisa enfatiza o protagonismo dos interventores na biocenose escolar. Concretamente reivindica a problemática do professor como pesquisador.

- As operações intelectuais utilizadas na pesquisa ressaltam a participação dos alunos. A pesquisa é democrática.

- A pesquisa favorece os processos simétricos de comunicação social e, para lográ-los, utiliza dinâmicas como o trabalho em equipe e a plenária, entre outras.

- A pesquisa suscita atitudes criticas muito apropriadas para superar os 
obstáculos ou dificuldades do ecossistema escolar, a solidariedade e o compromisso na solução dos problemas.

- A pesquisa usa técnicas e métodos próprios do paradigma ecológico, que são: a observação participativa, o respeito à complexi- dade natural, o desenho de enfoque progressivo, a pesquisa-ação, a indeterminação radical da pratica, o processo de triangulação e as técnicas flexíveis de coleta de informações.

Sobre os aspectos estruturais da A/I, apresentamos o quadro a seguir:

\section{Modelo de Diseño APRENDER INVESTIGANDO}

1 Descubrimiento del problema o conflicto.

2 Descripción del problema:

2.1. Lectura connotativa: para descubrir los sentimientos de los sujetos respecto al problema o conflicto a investigar.

2.2. Lectura denotativa o análisis de las características objetivas del problema, de los elementos de que consta, de sus partes y clases.

2.3. Lectura estructural o contextual:

- Encuadramiento del conflicto en categorías más abstractas: transcender de los hechos a los conceptos

- Análisis de las causas y consecuencias del conflicto.

3. Hipótesis: avance de una solución al problema.

4.Tratamiento interdisciplinar o globalizador del problema: actividades relativas a distintas áreas para profundizar en el significado del problema y / o para recalar en la información o conocimiento de ciertos temas del programa que interesen por su transcendencia, por su valor instrumental o por su imprescindibilidad instructivo-educativa.

5. Elección de las técnicas idóneas para la recogida de datas, tanto individuales como grupales.

6. Conclusiones de la investigación:

- Comprobación o desestima del problema.

- Compromiso individual y grupal a nivel local y / o a nivel nacional o internacional.

7. Informe de la investigación:

- Utilización de toda clase de gráficos y técnicas expresivas que den a conocer los resultados a la clase o al exterior de la misma.

Rojo, 1997, p. 160 
Feita essa exposição sobre a metodologia Aprender Investigando (A/I), tomamos a liberdade de apresentar uma descrição geral sobre sua aplicação, objetivando elucidar a integração possível entre a pedagogia de projetos e o processo de formação do professor pesquisador. Adiantamos, ainda, que não chegamos a executar por completo todos os passos da metodologia A/I, como será possível observar a seguir.

\subsection{DESCREVENDOAAPLICAÇÃO DA METODOLOGIA APRENDER INVESTIGANDO (A/I)}

Nosso primeiro contato com os futuros professores que foram alvos da aplicação da metodologia aconteceu de maneira diferente do habitual. Não nos preocupamos em, de imediato, apresentar a ementa da disciplina, a bibliografia e, por conseguinte, definir os critérios de avaliação para o semestre. Pelo contrário, começamos levantando questionamentos sobre a natureza do curso que eles estavam fazendo, tomando como referencial uma das características legitimadoras da identidade profissional descrita no projeto: ser professor pesquisador.

A partir dos resultados obtidos da estratégia adotada, não só começamos a esclarecer empiricamente em que incidia aquele tipo de profissional, mas também procuramos instigar ainda mais a inquietação dos futuros professores. Depois de deixá-los com a curiosidade aguçada, fizemos um breve seminário para explicar a metodologia que iria ser adotada. De imediato, foi possível perceber que muitos ficaram angustiados e até inseguros, por não conseguirem notar uma relação próxima entre o novo proposto e as antigas metodologias experienciadas.

Inicialmente nos preocupamos em apresentar o objetivo geral daquela metodologia, que incidia em

Investigar como se dá o processo de construção do conhecimento científico na formação de educadores pesquisadores, tomando como referencial estratégias de ensino-aprendizagem legitimadas a partir da indissociável relação pesquisa - ensino e da meta pesquisa.

Partindo do descrito no objetivo geral, começamos a dar sentido ao roteiro oriundo daquela metodologia, que aconteceu em um processo que denominamos de meta-pesquisa, ou seja, falamos de pesquisa em educação, adotando como procedimento a construção de projetos de pesquisa em educação.

Seguindo as orientações metodológicas recomendadas, aproveitamos as inquietações decorrentes dos nossos contatos iniciais com aqueles futuros professores. É o que podemos observar nos momentos descritos a partir de agora.

Quando nos propusemos a legitimar o problema ou conflito, apresentamos uma problematização geral (PG), que foi bastante evidenciada em momentos anteriores, da qual se originaram as problematizações específicas 
(PE). Procuramos instigar ainda mais os alunos (futuros professores) e, por conseguinte, fomos redimensionando as problematizações específicas às unidades do conteúdo programático da disciplina Pesquisa e Prática Pedagógica I. Em seguida, cada um dos PEQUENOS GRUPOS assumiu uma PE, a qual foi tomada como uma questão a ser razão de uma resposta de cunho científico, posteriormente.

Como conseqüência daquela prática, originaram-se alguns questionamentos, na condição de PG e de PEs:

P.G: Incide a pesquisa em um instrumento imprescindível para que a prática pedagógica do professor se torne eficaz?

PE1 - Que implicações podem ocorrer quando o pesquisador de questões educacionais não conhece, ou não aplica com propriedade o método, ao pesquisar um objeto/situação problema?

PE2 - Incide, como um dos pilares fundamentais no âmbito educacional, a pesquisa quantitativa? Quando, como e onde predomina?

PE3 - A pesquisa qualitativa é apenas mais um modismo em educação ou realmente tende a ser a abordagem mais eficaz?

PE4 - A pesquisa empírica tende mais a redimensionar o estudo de um objeto/situação-problema, ou não chega a isso, porque apresenta inúmeras limitações?

PE5 - A adoção de instrumentos de pesquisa em educação (questionário, entrevistas, observações) tem con- seguido trazer à superfície significativo nível de validez sobre o objeto ou situação-problema pesquisado?

Após definidos os problemas, partimos para sua descrição. Para tanto, nos ativemos em três níveis de leitura: a conotativa, a denotativa e a estrutural.

A leitura conotativa aconteceu a partir dos pequenos grupos formados anteriormente; os futuros professores expressaram seus sentimentos (expectativas, medos, frustrações etc.) a respeito do problema que elegeram ainda no item 1, como PE. Após o registro das informações externadas nos pequenos grupos, os alunos estavam de posse dos RELATÓRIOS sobre a experiência vivenciada.

$\mathrm{Na}$ leitura denotativa, pelo fato de estarem munidos dos registros obtidos na etapa anterior, os futuros professores procuraram dar continuidade ao relatório, a partir de um LEVANTAMENTO DE OPINIÕES dos próprios membros dos pequenos grupos a respeito da PE que estavam perseguindo. Procuraram dizer o que pensavam, agrupando suas idéias em categorias, contextualizando-as em um determinado tempo e espaço, assim como relacionando suas causas e possíveis conseqüências.

No momento da leitura estrutural ou contextual, houve o redimensionamento do RELATÓRIO, que teve como referencial uma PESQUISA BIBLIOGRÁFICA desenvolvida pelos próprios membros dos respectivos pequenos grupos, centrando-se em te- 
óricos que construíram conhecimentos e geraram conteúdos programáticos sobre a questão-problema.

Quando partimos para a elaboração de hipótese e ou/ possivel solução para o problema, cada um dos PEQUENOS GRUPOS, a partir dos resultados das discussões do seminário, centrou-se na PE que estava perseguindo, assim como nas respectivas categorias que a elas estavam imbricadas, para efeito de elaboração das hipóteses iniciais e ou/ questõesproblema para as quais pensaram em buscar as respostas devidas.

O tratamento globalizador do problema foi feito através de um SEMINÁRIO, organizado de acordo as diretrizes necessárias para aquela natureza de atividade acadêmica mencionada anteriormente. Cada um dos pequenos grupos ressignificou sua temática do projeto de pesquisa com os demais grupos, a partir da socialização dos conhecimentos específicos que fundamentaram teoricamente a PE que estavam perseguindo.

Após ter sido elaborada a fundamentação teórica do projeto de pesquisa em construção, os futuros professores, em pequenos grupos, definiram o método e as TÉCNICAS DE COLETA DE DADOS, para efeito de busca de respostas para o problema que pesquisaram. Feito isto, iniciaram o processo de estudo de todas as etapas dos respectivos projetos, para efeito de averiguação de possíveis defíciências, a partir da minha orientação.

Desenvolvidos os procedimentos metodológicos, foram construídos cinco projetos de pesquisa que, em um seminário de projetos, os grupos apresentaram como suas respectivas produções, abrindo espaço para comentários e sugestões. Terminada essa atividade, começamos uma oficina de projetos, tomando como base toda a experiência obtida no processo coletivo anteriormente descrito. As respectivas produções individuais, por sua vez, resultaram nos projetos de pesquisas individuais, a serem executados durante o período de estágio supervisionado dos futuros professores.

O mais impressionante foi que cada um dos futuros professores, a partir do primeiro contato com a escola em que iriam estagiar, construíram seus diagnósticos, que serviram tanto para definir a temática de sua pesquisa, quanto para legitimar as categorias norteadoras que ajudariam na construção do marco teórico. Atualmente, todos os futuros professores do quinto período estão em processo de consubstanciamento de seus respectivos projetos. A fim de conhecer as impressões dos futuros professores sobre a prática pedagógica em questão, colhemos alguns depoimentos, que apresentaremos no item seguinte.

\section{AS IMPRESSÕES DA METODOLOGIAA/I, DESCRITA PELOS FUTUROS PROFESSORES}

Vale ressaltar que as referidas criações coletivas serviram apenas de 
pretexto para as criações individuais, ocorridas em momento posterior. Para que se tenha uma breve compreensão de como a metodologia influenciou no processo de formação dos futuros educadores, apresentamos os depoimentos que coletamos na avaliação final da relatada experiência pedagógica.

Que comentários você tece a respeito da metodologia que foi adotada na disciplina Pesquisa e Prática Pedagógica?

A metodologia apresentada foi de extrema importância, pois nos deu uma visão de como construir um projeto a partir de uma inquietação, isto foi algo que me ajudou bastante.

Particularmente achei fantástica, não achava que trabalhar com projeto poderia ser tão prático.

Eu gostei muito, pois aprendi que a pesquisa, a elaboração de projetos não é algo tão doloroso. Pelo contrário, é prazeroso, principalmente quando vemos a nossa pesquisa pronta.

A metodologia foi excelente, pena que o tempo foi curto para ser trabalhado. Com esta percebemos que o projeto de pesquisa não é um bicho-de setecabeças.

No começo, para mim, foi muito confuso, por não saber aonde o senhor queria chegar nos transmitindo tantas informações, que em certos momentos achava que não iriam me servir. Hoje sei que precisei delas para me dar suporte em minha pesquisa.

A respeito da metodologia $\mathrm{A} / \mathrm{I}$ adotada na disciplina Pesquisa e Prá- tica Pedagógica I, as opiniões dos futuros professores,em sua maioria, apresentam-se favoráveis a ela. Dentre os aspectos referentes a esta observação, podemos, inclusive, detectar falas que se sustentam por pares simétricos como: inquietação e construção, aprendizagem e prazer, satisfação e percepção de conhecimento construído.

Considerando os pares simétricos como elementos norteadores do processo ensino-aprendizagem daqueles futuros professores, teremos a oportunidade de detectar que não houve apenas inovação na metodologia aplicada, mas sim quebra de paradigmas que conduziram os alunos não só a refletirem sobre o tipo de tratamento que têm dado ao conhecimento no decorrer de sua formação, mas também a perceberem que ser pesquisador pode ser uma prática possível de legitimar sua identidade pessoal e profissional. Dessa maneira, a pedagogia de projetos assume sua condição antropológica, pois o projeto do autor começa a ganhar vida própria, retroalimentando-se a partir da vida daquele que o concebeu. Não há necessidade de pensar apenas a execução de um conjunto de ações para se atingir a um fim. É de extrema importância que tanto a criatura (o projeto), quanto o criador (seu autor), busquem estratégias de ressignificação para suas vidas, tomando como referencial a necessidade de estabelecimento das relações de interdependência com o próximo e com o 
meio, a fim de problematizar situações do cotidiano e criar alternativas de sobrevivências centradas no reconhecimento da diversidade como um possível caminho para se chegar à unidade.

Que impressões você tinha a respeito da pesquisa vinculada à prática pedagógica e quais você tem atualmente?

Antes não tinha opinião formada, mas hoje posso dizer que para fazer pesquisa é necessário tempo, disposição, determinação e força de vontade.

Tinha a impressão de que pesquisar era algo extremamente complicado, elaborado somente por cientistas ou pessoas que tivessem um conhecimento profundo de muitos anos sobre a problemática. Atualmente este pensamento mudou, pois fazer pesquisa é importante e tem todo um processo de elaboração e como aluno é possivel eu me inserir neste processo.

Antes eu sentia medo, pois a pesquisa parecia distante da realidade educacional. Hoje percebo que é possivel pesquisar sobre as dificuldades para contribuir com a prática educacional.

É possível perceber, nas falas acima apresentadas, o quanto o pragmatismo, que legitima e potencializa as novas tecnologias da era da automação, predomina no âmbito escolar. Ademais, tende sempre a estruturarse como um princípio quase que ortodoxo de que o conhecimento está para ser reproduzido e internalizado, para efeito de execução de uma tarefa posterior.
Dentre as conseqüências desse paradigma pragmático está a possibilidade de não se experimentar as façanhas de desconstruir e reconstruir conhecimentos, o que, por sua vez, gera o distanciamento maior de se compreender e apreender diferentes mecanismos capazes de incrementar o que podemos chamar de fomento científico. Portanto, nessa perspectiva, como bem legitimaram os positivistas, fazer ciência ainda é tarefa daqueles que conseguem a façanha de se neutralizarem e se isolarem de tudo e de todos, para efeito da busca de resultados decorrentes dos testes de determinados experimentos.

A escola, por sua vez, ainda não consegue aguçar a inquietação daqueles que nela estão para fazer ciência. Sendo assim, passa a tornar-se um espaço em que a protagonização do processo histórico é mérito daqueles que quantificam pressupostos teóricos, aplicando-os com propriedade em suas retóricas, ignorando possibilidades de, pelo menos, alinhaválos com suas práticas pedagógicas.

Romper as respectivas barreiras é imprescindível, na atual conjuntura em que nos encontramos. Para tanto, na condição de professores que não conseguem desvincular a pesquisa do fazer pedagógico, nada melhor do que lançarmos mão de alternativas inovadoras e criativas, assim como de trocas de experiências exitosas, de maneira que a inquietação de ajudar pessoas a construir um mundo melhor não pereça. 
Que vantagens e desvantagens são possíveis detectar em ser professor pesquisador?

É interessante porque este tipo de educador está sempre estudando, avaliando e analisando a educação no seu processo. Mas é difícil ser este tipo de educador porque a escola não disponi-biliza de tempo para que ele pratique todas estas ações.

Este tipo de professor pode contribuir para a formação do aluno de forma efetiva e produzir conhecimentos científicos advin-dos da prática-teoria. O que pode também ocorrer de desvantagem é que ele pode deixar de colocar em prática toda a teoria obtida na sua pesquisa.

A grande vantagem do educador pesquisador é que ele deverá estar sempre atualizado, não se acomodando diante dos problemas. Talvez uma desvantagem seja não a pesquisa como uma ajuda para mudar a realidade principalmente da sua sala de aula.

No que diz respeito às vantagens e desvantagens em ser professor pesquisador, podemos observar nas falas apresentadas que se considera interessante o referencial identitário proposto, porque possibilita oportunidades de inovações e atualização, e retroalimenta as inquietações sobre os seres, no contexto em que estão inseridos. Por outro lado, em seguida, são apresentados entraves significativos que são, inclusive, reflexos de situações do cotidiano escolar que há muito alimentam a permanência de um status quo favorável àqueles que ainda defendem a crença de que o âmbito escolar está para o ensino, podendo ser objeto de estudo, desde que $o$ pesquisador consiga descentrar-se e manter-se neutro em relação a ele.

\section{CONSIDERAÇÕES FINAIS}

Apesar de estarmos terminando nossa trajetória cientes das restrições na aplicação da metodologia A/I, detectamos alguns avanços e desafios que tornam evidentes a importância da integração da pedagogia de projetos, como efeito legitimador na construção do referencial identitário do professor pesquisador. Para efeito de continuidade do respectivo estudo, é de nosso interesse, neste momento, apresentar alguns avanços e desafios descobertos no decorrer desse processo. Na condição de avanços, constatamos os seguintes:

. Ressignificação do espaço de sala de aula a partir de um clima democrático e da troca de experiências sobre inquietações, frustrações e dificuldades relacionadas à pesquisa.

- Valorização dos elementos e ações do espaço de sala de aula na descoberta do objeto/problema de pesquisa.

. Apreensão da pedagogia de projetos a partir da condição de uma metodologia alternativa de formação.

. Sensibilização e compreensão da importância da concepção de professor pesquisador como uma alternativa exitosa de formação docente. 
. Rompimento com o paradigma de que a pesquisa precisa ser uma ação isolada e neutra, centrando-se apenas em teorias e ignorando-se a crença de que o espaço de sala de aula pode ser seu laboratório de pesquisa.

Com referência aos desafios detectados, percebemos que ainda há muito caminho a percorrer, muitas barreiras a serem transpostas. Dentre elas, apresentamos algumas que consideramos emergenciais:

. A dificuldade que os alunos possuem em conceber a descoberta, amadurecimento e apreensão do objeto/ problema a ser pesquisado como um processo, que foge à lógica pragmática e sistematizadora da nosso sociedade capitalista.

. A limitação na compreensão do processo epistemológico que precisa ser utilizado para legitimar a interdisciplinaridade como uma alternativa eficaz para a compreensão e apreensão do objeto/problema da pesquisa.

. O planejamento multifacetado das disciplinas que constituem o período acadêmico, gerando excesso de atividades de avaliação e impossibilidades de compreensão da natureza formativa do respectivo período.

. A necessidade de tranversalizar a pedagogia na condição de ciência, tomando como base um planejamento conjunto, a partir do efetivo exercício da interdiscipli-naridade.

Após expor os aspectos denominados de avanços e desafios, ampliamos nossas inquietações, pautados na crença da pedagogia de projetos como alternativa criativa e prazerosa na formação de professores pesquisadores. Decorrente disto, alertamos também para a necessidade de "reintegrar prioritariamente nos projetos humanos, tanto existenciais quanto técnicos, a dimensão histórica que sua técnica não deveria ter abandonado (BOUTINETI, 2002, p. 289)"'. Acreditamos ser possivel a mencionada reintegração no contexto escolar, a partir da adoção de estratégias de ensinoaprendizagem centradas na interdisciplinaridade, de maneira que não seja "mais possivel cada professor pensar seu curso isoladamente, em sua casa. É muito pouco. Assim não dá conta dos problemas levantados pelos nossos alunos e pela nossa sociedade (ALMEIDA, 2000, p. 40)." Contudo, o primeiro passo é "perceber, portanto, que os gestos que inventam uma organização escolar e os gestos que inventam uma aula não são diferentes dos gestos que inventam o fazer ciência e pesquisa (MEKSENAS, 2002, pág. 27)."

\section{REFERÊNCIAS}

ALMEIDA, F. J. de. Projetos e ambientes inovadores. Secretaria de Educação a Distância: Seed, 2000.

BACHELARD, G. A formação do espírito científico. Rio de Janeiro: Contraponto, 1996.

BOUTINETI, J. P. Antropologia do projeto. Tradução de Patrícia Chitonni Ramos. Porto Alegre: Artmed, 2002. 
CLELAND, D. I. Gerência de projetos. Rio de Janeiro: Reichmann \& Affonso, 2002.

HERNÁNDEZ, F. A organização do currículo por projetos de trabalho. Tradução de Jussara Haubert Rodrigues. Porto Alegre: ArtMed, 1998.

MEKSENAS, P. Pesquisa social e ação pedagógica: conceitos, métodos e práticas. São Paulo: Loyola, 2002.

ROJO, M. R. Hacia una didáctica crítica. Madrid: Editorial La Muralla, S.A, 1997.

TRIVIÑOS, A. N. S. Introdução à pesquisa em ciências sociais: a pesquisa qualitativa em educação. São Paulo: Atlas, 1987.

YUS, R. Temas transversais: em busca de uma nova escola. Tradução de Ernani F. da F. Rosa. Porto Alegre: ArtMed, 1998.

Encaminhado em: 21/03/2005

Aceito em: 28/11/2005 